$$
\begin{aligned}
& \text { تاثير ميدان مغناطبسى و اسموير ابمينَ بر جوانهزنى و رويش بذر بنه }
\end{aligned}
$$

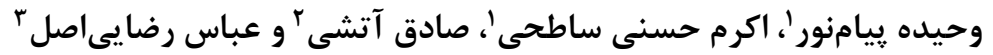

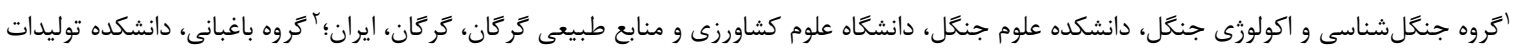

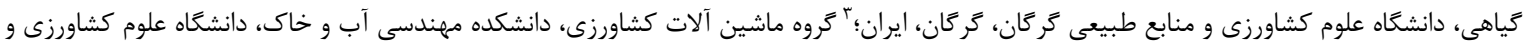

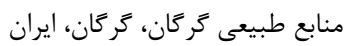

$$
\begin{aligned}
& \text { payamnoor@gau.ac.ir مسئول مكاتبات: وحيده پيام نورن }
\end{aligned}
$$

جكيده. تحقيق حاضر با هدف بهبود شاخصهاى جوانهزنى و عملكرد اوليه بذر بنه با بررسى تأثير احتمالى ميدان مغناطيسى و همجنين تيمارهاى بهبود دهنده

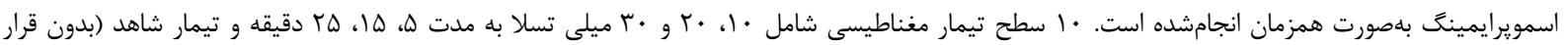

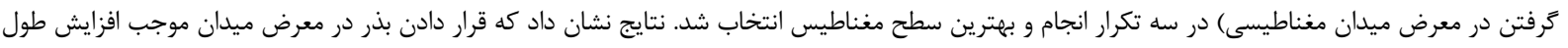

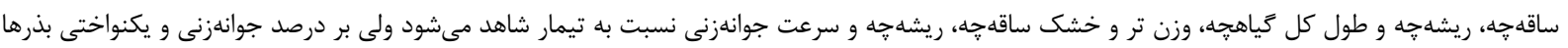

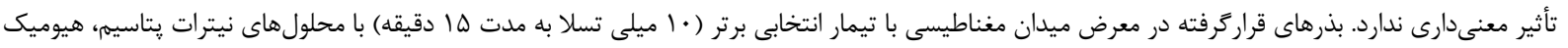

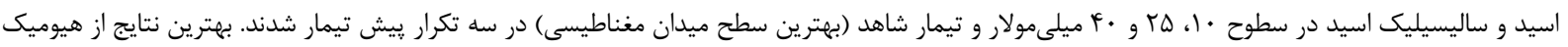

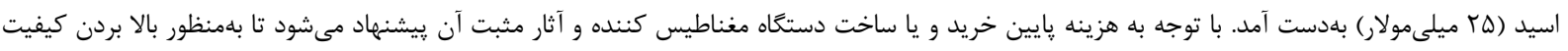

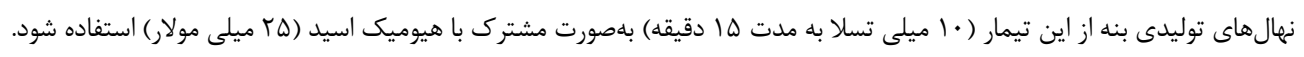
وازههاى كليدى. ساليسيليك اسيد، عملكرد اوليه بذر، ميلى تسلا، نيترات يتاسيم، هيوميك اسيد

\title{
The effects of magnetism and osmopriming on seed germination and vegetative characteristics of Pistacia atlantica
}

\author{
Vahide Payamenoor ${ }^{1}$, Akram Hasani Satehi ${ }^{1}$, Sadegh Atashi ${ }^{2}$ \& Abbas Rezaii Asl ${ }^{3}$ \\ ${ }^{1}$ Department of Forest Ecology and Silviculture, Faculty of Forest Sciences, Gorgan University of Agricultural Sciences \\ and Natural Resources, Gorgan, Iran; ${ }^{2}$ Department of Horticulture, Faculty of Plant Production, Gorgan University of \\ Agricultural Sciences and Natural Resources, Gorgan, Iran; ${ }^{3}$ Department of Agricultural Machinery, Faculty of Water \\ and Soil Engineering, Gorgan University of Agricultural Sciences and Natural Resources, Gorgan, Iran
}

Correspondent author: Vahide Payamenoor, payamnoor@gau.ac.ir

\begin{abstract}
The present study aimed to increase the seed germination and the initial performance of pistachio seeds by investigating the effects of the magnetic field and osmopriming treatments simultaneously. 10 treatment levels of 10, 20 and $30 \mathrm{mT}$ for 5, 15, 25 minutes and 1 control treatment (without exposure to a magnetic field) were performed in three replicates and the best level of magnetic surface was selected. The results showed that seeds subjected to the magnetic field showed an increase in plumule length, radicle length, total length of seedlings, fresh and dry weight of plumule as well as radicle and germination speed compared with the control treatment. However, there was no significant difference in the germination percentage and uniformity of seeds. Magnetized seeds, with the superior selective treatment $(10 \mathrm{mT}$ for 15 minutes), were primed with solutions of potassium nitrate, humic acid and salicylic acid at levels of 10, 25 and $40 \mathrm{mM}$ and a control level (the best level of magnetism) in three replicates. The best result was obtained from humic acid $(25 \mathrm{mM})$. With regard to the low cost of the purchase or construction of magnetic devices and their positive effects, their application could be recommended (10 mT for 15 minutes) combined with the humic acid $(25 \mathrm{mM}))$ so that the quality of pistachio seedlings production would be increased.
\end{abstract}

Keywords. humic acid, millitesla, potassium nitrate, salicylic acid, seed initial performance 
Cakmak). نتايج برخى آزمايشها نشان داده است كه ميدان

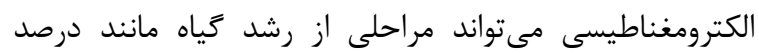

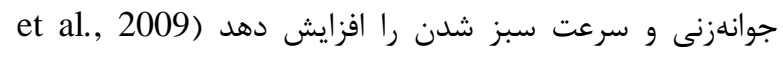
Martinez

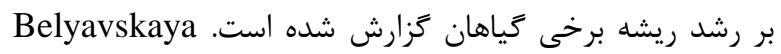

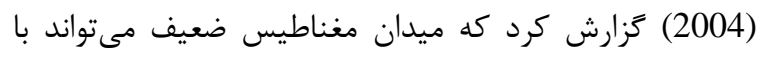

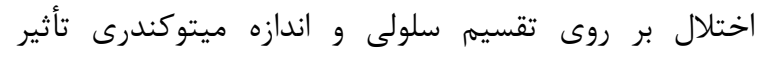

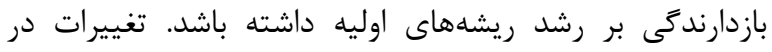

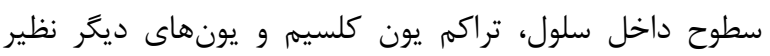

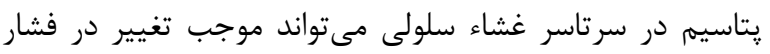

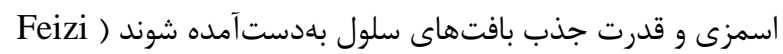
معرض ق Rezvani Moghaddam, 2011 معرض قرار دادن بذر و گياهان با ميدان مغناطيسى نشاندهنده

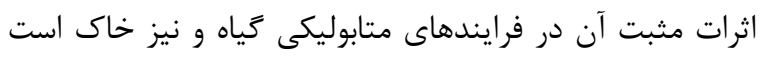

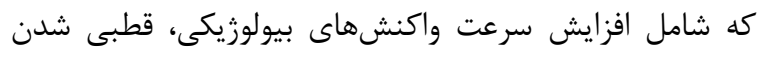

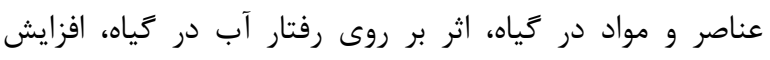
تحمل به تنش كرما و خشكى، افرايش قدرت جذب آب آب و مواد

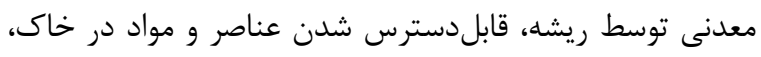

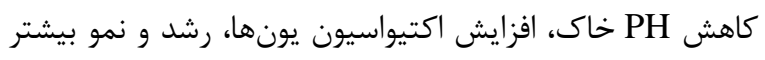

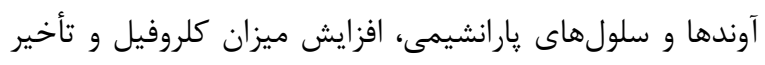
در يِيرى، كاهش خسارت بيمارىها، بهبود رشد و نمو و عملكرد Fياه مىشود (Feizi \& Rezvani Moghaddam, 2011). مطالعه زيادى در خصوص بردي (رسى ميدان مغناطيسى بر روى

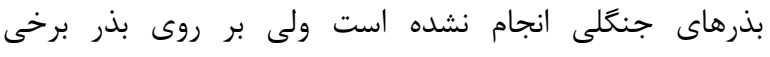

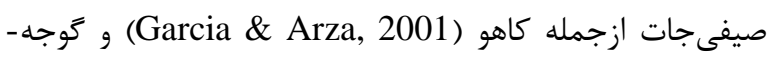
فرنكى (Abou El-Yazied et al., 2011) تحقيقاتى صورت كرفته كه نشاندهنده اثرات مثبت اين تيمار در بهببود عملكرد

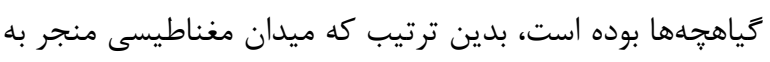

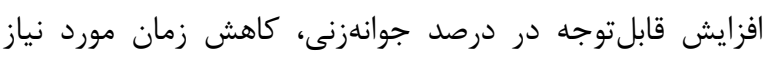

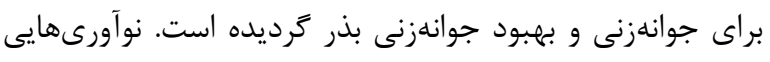

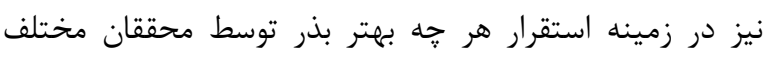

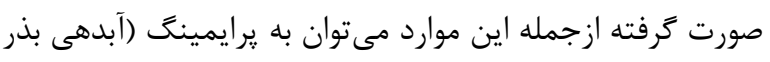

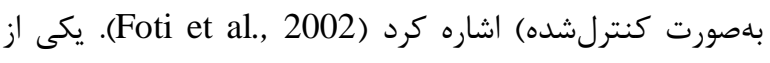

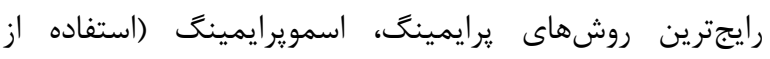

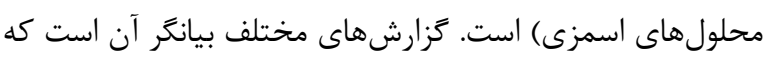

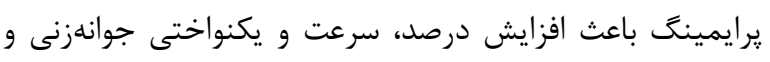

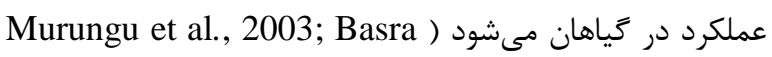
(et al., 2004

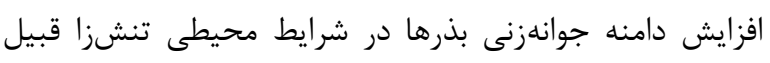

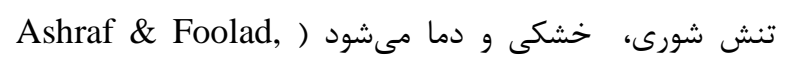

مقدمه

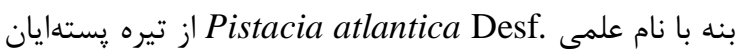
(Anacardiaceae)

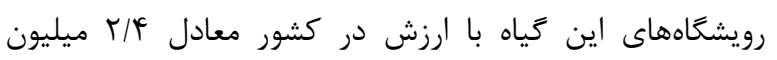

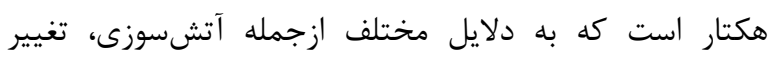

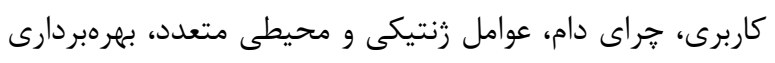

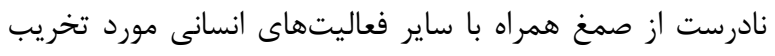

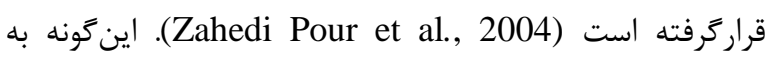

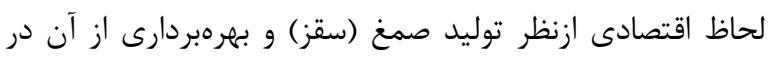

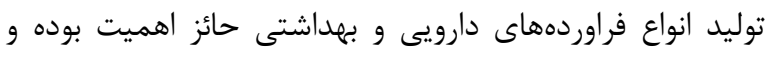

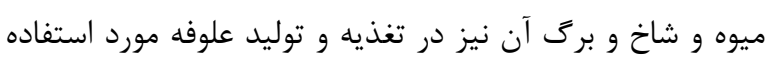

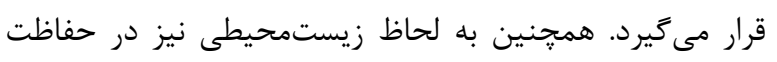

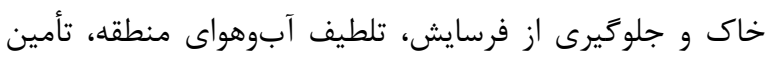

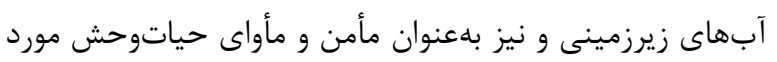

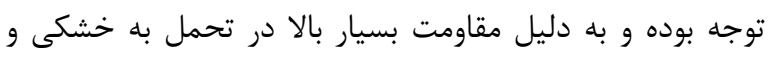

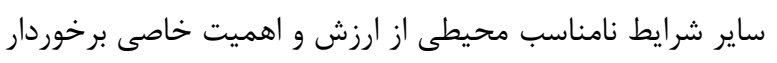

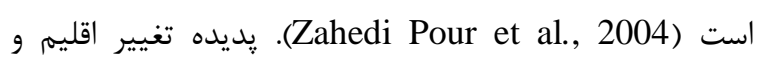

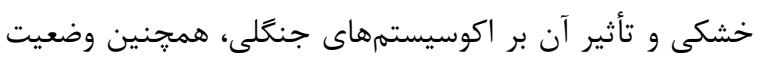
نامناسب اكوسيستم جنكلى زاكرس و ضرورت استير استفاده از كونه-

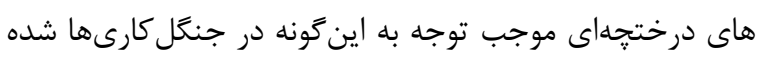

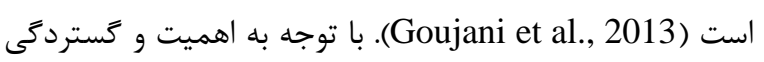
كَونهاى يسته وحشى در جنَّلهاى خارج از محدوده شمال

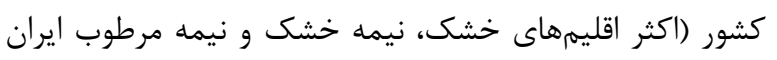

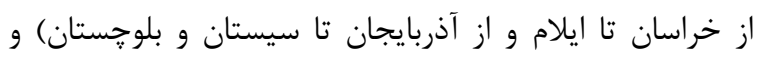

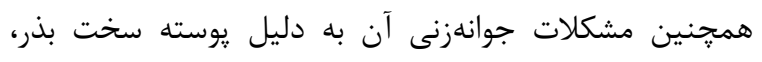

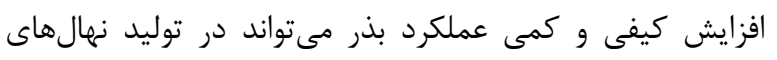
بهتر مفيد واقع شود. تحريك گياهان با استفاده از ميدان مغناطيسى بهتازئى بلعنوان راهكارى جهت افزايش كميت و كيفيت عملكرد مورد

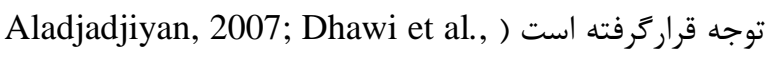
قطي 2009 ; Vasilevski, 2003

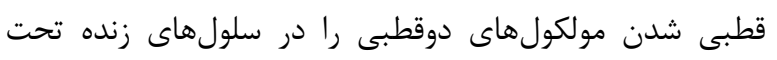
تأثير قرار مىدهد (Dhawi et al., 2009; Kordas, 2002) خصوصيات مغناطيسى مولكولها، توانايى آنها را براى جذب انب و

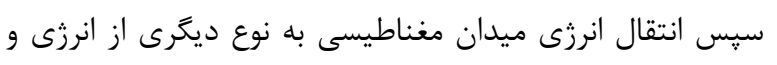

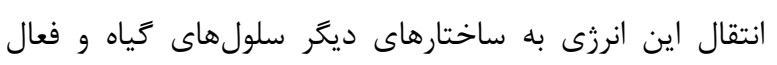
نمودن آنها تعيين مينمايد (Aladjadjiyan, 2010). اثرات

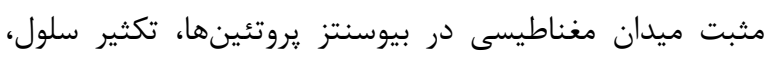

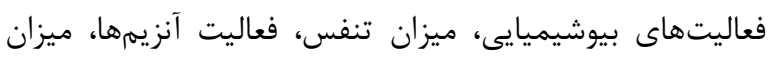

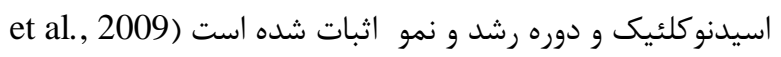


تيمارشده بلصورت 1 اتايى در يترىديشها قرار گرفتند. شمارش

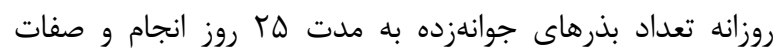

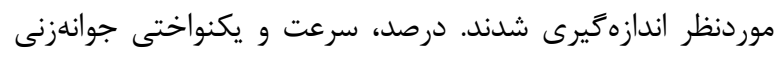

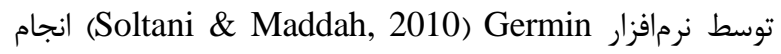
شد. به منظور تجزيه تحليل دادهها از نرمافزار 16 SPSS 16 استفاده

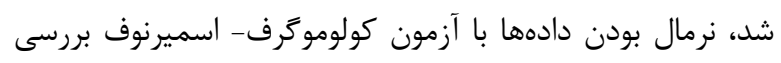
شد. براى مقايسه تيمارها از طرح فاكتوريل دو دون عامله (ميدان مغناطيس در زمانهاى مختلف) و جهت مقايسه ميانگين از آزمون קند دامنه دانكن استفاده كرديد.

نتايج نتايج حاصل از تجزيه واريانس دادهها نشان داد كه سطوح

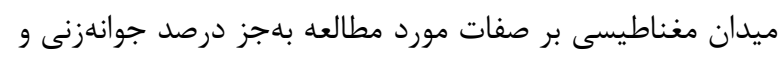

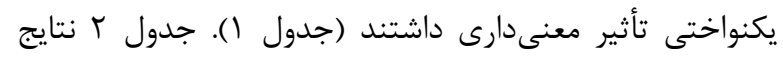

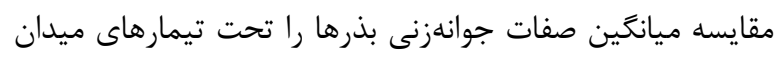

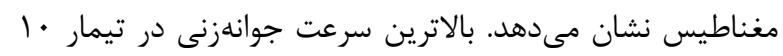

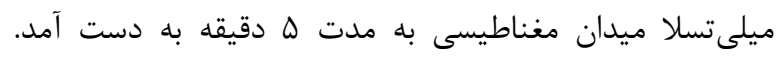

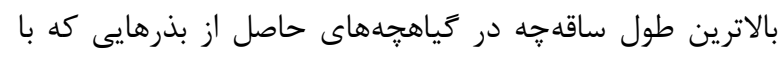
قر ب r.

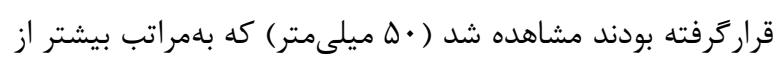

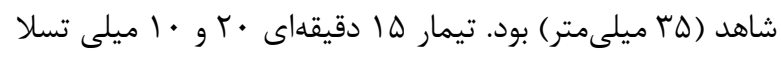

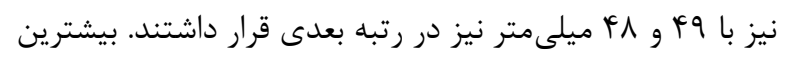

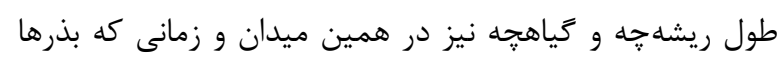

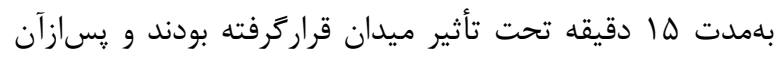

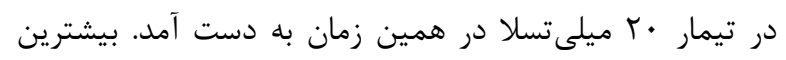

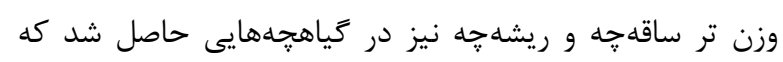

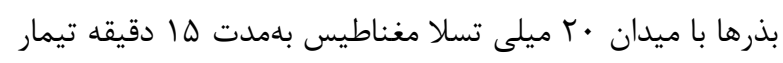

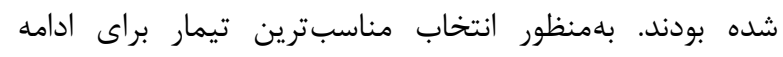

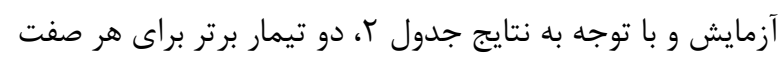

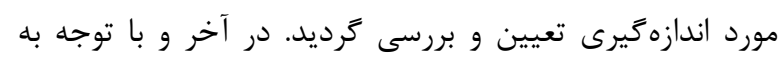

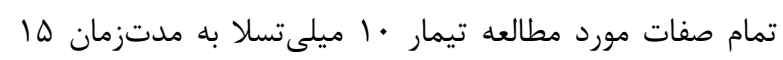

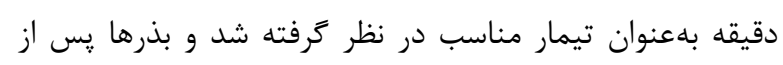

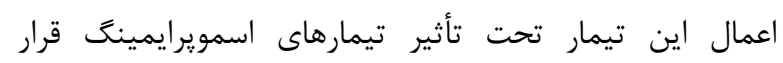

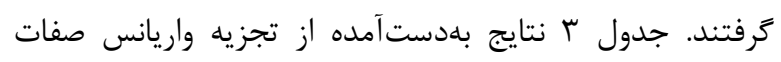

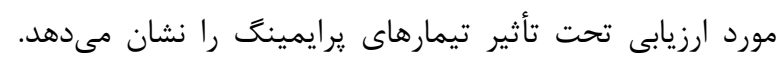

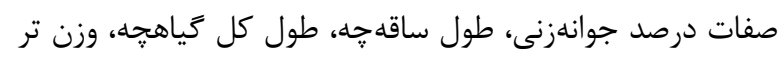

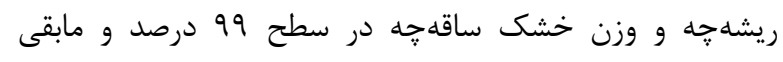

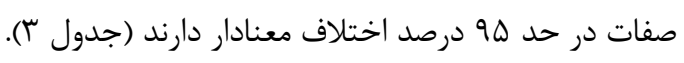

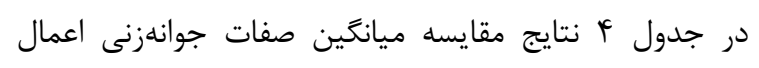
تيمارهاى يرايمينَ بر صفات جوانهزنى بذرهاى مغناطيس شده مئن
2005). در اين خصوص اثرات مثبت بسيارى از محلولهاى

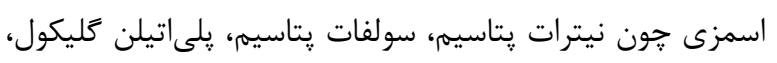

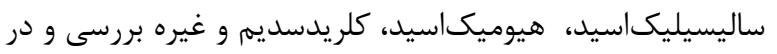

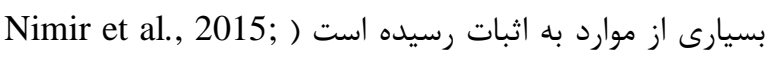
Sheteiwy et al., 2015; Sheteiwy et al., 2017; Khan et al., 2017; Singh et al., 2014; Sedaghathoor et al., 2015). هدف از انجام اين مطالعه بررسى امكان بهبود صفات

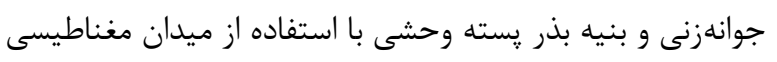

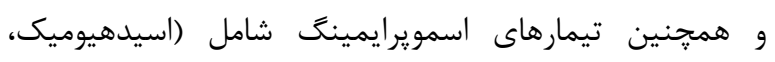
نيترات يتاسيم و اسيدساليسيليك) است.

\section{مواد و روش ها}

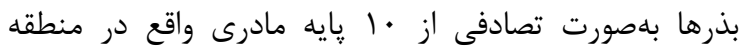

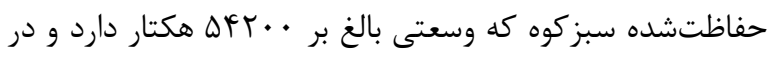

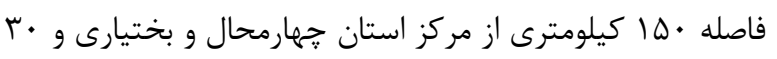

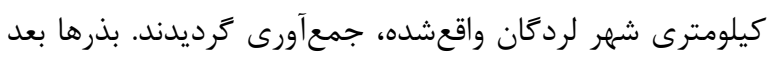

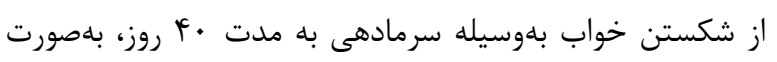

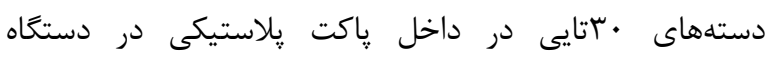

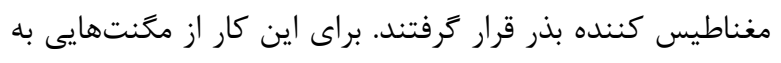

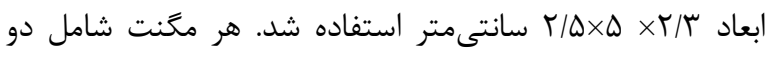
قطعه بود (بهصورت جفت) كه در حالت دافعه (قطب هادهاى همنام

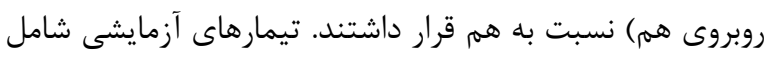

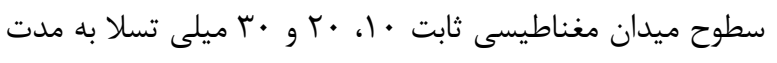

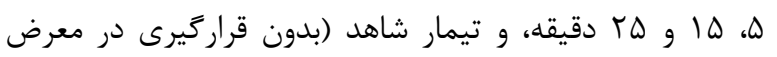

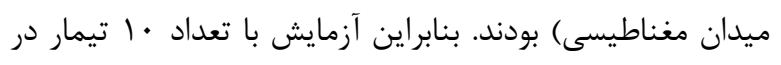

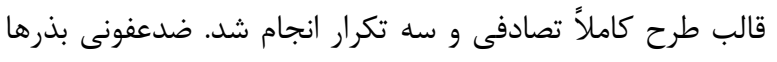

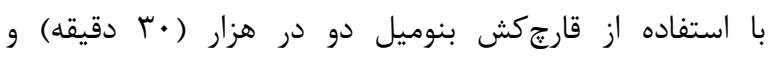

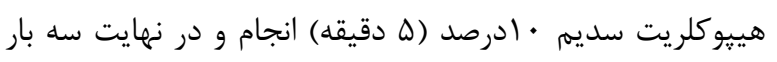

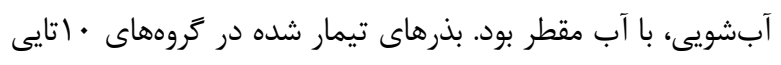

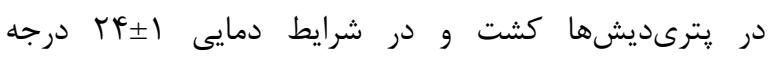

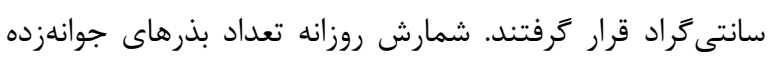

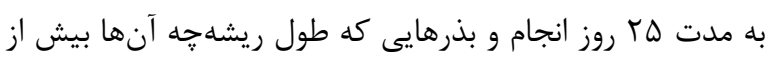

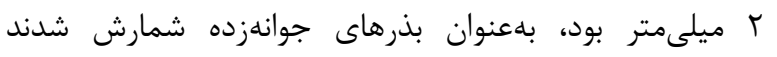

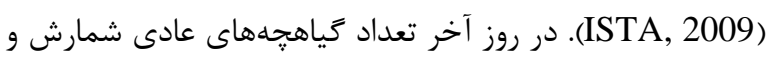

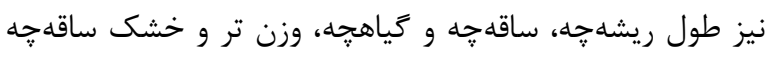

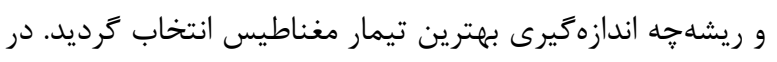

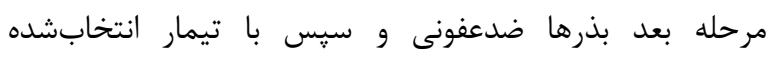

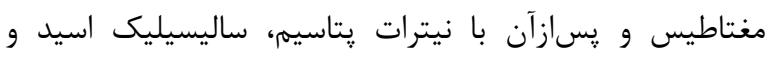

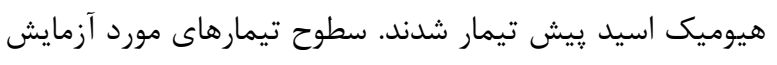

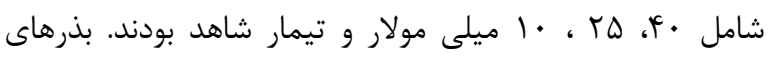


جدول ا- تجزيه واريانس اعمال سطوح مغناطيس بر صفات جوانهزنى بذرهاى بنه.

Table 1. Analysis variance of applying magnetic field treatment on pistachio seeds germination.

\begin{tabular}{|c|c|c|c|c|c|c|c|c|c|c|c|}
\hline $\begin{array}{c}\text { Shoot } \\
\text { dry } \\
\text { weight } \\
(\mathrm{g})\end{array}$ & $\begin{array}{l}\text { Root dry } \\
\text { weight } \\
\text { (g) }\end{array}$ & $\begin{array}{c}\text { Root } \\
\text { fresh } \\
\text { weight } \\
(\mathrm{g})\end{array}$ & $\begin{array}{c}\text { Shoot } \\
\text { fresh } \\
\text { weight } \\
(\mathrm{g})\end{array}$ & $\begin{array}{c}\text { Total } \\
\text { length of } \\
\text { seedling } \\
(\mathrm{mm})\end{array}$ & $\begin{array}{l}\text { Root } \\
\text { length } \\
(\mathrm{mm})\end{array}$ & $\begin{array}{c}\text { Stem } \\
\text { Length } \\
(\mathrm{mm})\end{array}$ & $\begin{array}{c}\text { Uniformi } \\
\text { ty }\end{array}$ & $\begin{array}{c}\text { Germinatio } \\
\text { n rate }\end{array}$ & $\begin{array}{c}\text { Germinatio } \\
\mathrm{n} \%\end{array}$ & df & $\begin{array}{c}\text { Sources } \\
\text { of } \\
\text { changes }\end{array}$ \\
\hline $0.0001^{*}$ & $0.00001^{*}$ & $0.026^{*}$ & $0.029^{*}$ & $1538.84^{*}$ & $938.02^{*}$ & $102.76^{*}$ & $4247.2^{\mathrm{ns}}$ & $"$ & $304^{\mathrm{ns}}$ & 9 & treatme \\
\hline 0.0001 & 0.00001 & 0.025 & 0.02 & 1123.49 & 87.82 & 60.90 & 80.31 & $\begin{array}{l}0.00005886 \\
0.00006538 \\
\end{array}$ & 526.66 & 20 & $\begin{array}{c}\text { nt } \\
\text { error }\end{array}$ \\
\hline
\end{tabular}
* وجود اختلاف معنى دار در سطح ه • • و ns عدم معنى ارى را نشان مىدهد.

"significant at $0<0.5$ level, ${ }^{\text {ns }}$ non-significant

جدول r - مقايسه ميانگين تيمارهاى ميدان مغناطيسى بر صفات جوانهزنى بذرهاى بنه.

Table 2. Mean comparison of magnetic field treatments on pistachio seeds germination.

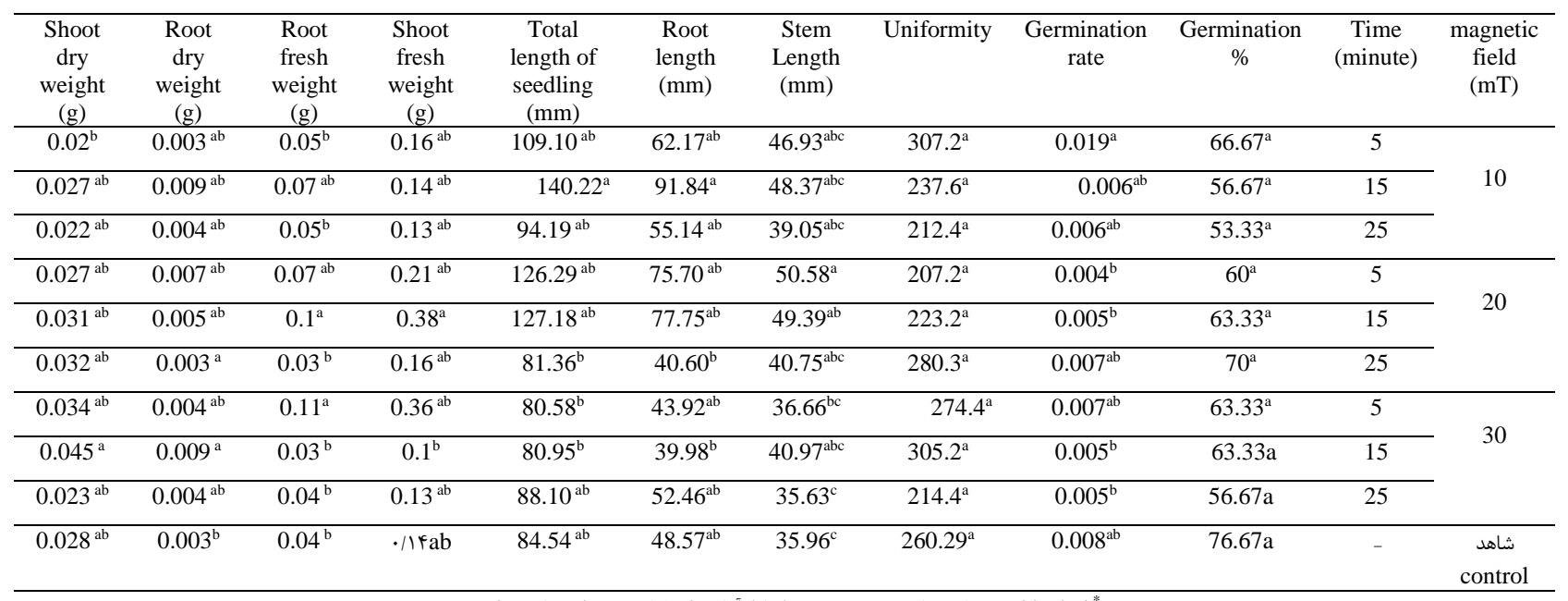

"اعداد داراى حروف مشابه در هر ستون به لحاظ آمارى اختلاف معنى دارى باهم ندارند.

*significant at $0<0.5$ level, ${ }^{\text {ns }}$ non-significant

جدول بـ تجزيه واريانس اعمال تيمارهاى اسمويرايمينَ بر صفات جوانهزنى بذرهاى بنه (تيمار شده با • إ ميلى تسلا به مدت ها دقيقه).

Table 3. Variance analysis results of applying osmopriming on pistachio seed germination (treated with $10 \mathrm{mT}$ for 15 minutes).

\begin{tabular}{|c|c|c|c|c|c|c|c|c|c|c|c|}
\hline $\begin{array}{l}\text { Shoot } \\
\text { dry } \\
\text { weight } \\
(\mathrm{g})\end{array}$ & $\begin{array}{c}\text { Root } \\
\text { dry } \\
\text { weight } \\
(\mathrm{g})\end{array}$ & $\begin{array}{c}\text { Root } \\
\text { fresh } \\
\text { weight } \\
(\mathrm{g})\end{array}$ & $\begin{array}{c}\text { Shoot } \\
\text { fresh } \\
\text { weight } \\
(\mathrm{g})\end{array}$ & $\begin{array}{c}\text { Total } \\
\text { length } \\
\text { of } \\
\text { seedling } \\
\text { (mm) }\end{array}$ & $\begin{array}{l}\text { Root } \\
\text { length } \\
(\mathrm{mm})\end{array}$ & $\begin{array}{c}\text { Stem } \\
\text { Length } \\
(\mathrm{mm})\end{array}$ & Uniformity & $\begin{array}{l}\text { Germination } \\
\text { rate }\end{array}$ & Germination $\%$ & df & $\begin{array}{c}\text { Sources of } \\
\text { changes }\end{array}$ \\
\hline $0.00018^{\text {*** }}$ & $0.0031^{*}$ & $0.00034^{* * *}$ & $0.0011^{*}$ & $133.93^{* * *}$ & $183.43^{*}$ & $216.07^{\text {*** }}$ & $952.37^{*}$ & $0.000085^{*}$ & $645.95^{* * *}$ & 9 & treatment \\
\hline 0.000027 & 0.001 & 0.000055 & 0.00035 & 34.05 & 59.82 & 24.4 & 791.94 & 0.000027 & 145.18 & 20 & error \\
\hline 26.94 & 36.67 & 23.45 & 15.09 & 11.34 & 18.7 & 11.38 & 37.76 & 23.95 & 18.65 & - & $(\mathrm{CV} \%)$ \\
\hline
\end{tabular}




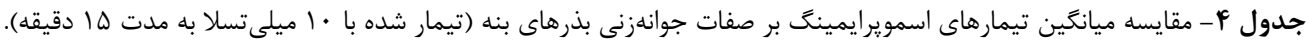

Table 4. Mean comparison of applying osmopriming on pistachio seeds germination (treated with $10 \mathrm{mT}$ for 15 minutes).

\begin{tabular}{|c|c|c|c|c|c|c|c|c|c|c|c|}
\hline $\begin{array}{l}\text { Shoot dry } \\
\text { weight } \\
\text { (g) }\end{array}$ & $\begin{array}{l}\text { Root dry } \\
\text { weight } \\
\text { (g) }\end{array}$ & $\begin{array}{c}\text { Root } \\
\text { fresh } \\
\text { weight } \\
(\mathrm{g})\end{array}$ & $\begin{array}{c}\text { Shoot } \\
\text { fresh } \\
\text { weight (g) }\end{array}$ & $\begin{array}{l}\text { Total } \\
\text { length of } \\
\text { seedling } \\
(\mathrm{mm})\end{array}$ & $\begin{array}{c}\text { Root } \\
\text { length } \\
(\mathrm{mm})\end{array}$ & $\begin{array}{c}\text { Stem } \\
\text { Length } \\
(\mathrm{mm})\end{array}$ & Uniformity & $\begin{array}{l}\text { Germination } \\
\text { rate }\end{array}$ & Germination $\%$ & & treatment \\
\hline $0.024^{\mathrm{d}}$ & $0.15^{\mathrm{a}}$ & $0.028^{\mathrm{cd}}$ & $0.142^{\mathrm{ab}}$ & $56.36^{\mathrm{ab}}$ & $31.22^{\mathrm{dc}}$ & $51.75^{\mathrm{ab}}$ & $78.67^{\mathrm{ab}}$ & $0.031^{\mathrm{a}}$ & $75^{\mathrm{ab}}$ & 40 & \multirow{3}{*}{$\begin{array}{l}\text { potassium } \\
\text { nitrate }\end{array}$} \\
\hline $0.025^{a b}$ & $0.08^{\mathrm{bc}}$ & $0.039^{\mathrm{abc}}$ & $0.142^{\mathrm{ab}}$ & $58^{\mathrm{a}}$ & $36.8^{\mathrm{bcd}}$ & $53^{\mathrm{a}}$ & $44.67^{b}$ & $0.024^{\mathrm{abc}}$ & $77.08^{\mathrm{ab}}$ & 25 & \\
\hline $0.022^{\mathrm{bc}}$ & $0.103^{\mathrm{ab}}$ & $0.031^{\text {bcd }}$ & $0.129^{\mathrm{abcd}}$ & $39.66^{d}$ & $53.5^{\mathrm{a}}$ & $26.16^{\mathrm{e}}$ & $56.48^{\mathrm{b}}$ & $0.025^{\mathrm{ab}}$ & $62.5^{\mathrm{bc}}$ & 10 & \\
\hline $0.012 \mathrm{~d}^{\mathrm{e}}$ & $0.081^{\mathrm{bc}}$ & $0.037^{\mathrm{abc}}$ & $0.138^{\mathrm{abc}}$ & $46.66^{\mathrm{bcd}}$ & $28.66^{\mathrm{d}}$ & $41.16^{\mathrm{dc}}$ & $79.77^{\mathrm{ab}}$ & $0.022^{\mathrm{abc}}$ & $58.33^{\mathrm{bc}}$ & 40 & \multirow[t]{3}{*}{ humic acid } \\
\hline $0.034^{\mathrm{a}}$ & $0.11^{\mathrm{ab}}$ & $0.048^{\mathrm{a}}$ & $0.132^{\mathrm{abcd}}$ & $58.83^{\mathrm{a}}$ & $49^{\mathrm{ab}}$ & $42.66^{\mathrm{dc}}$ & $75.63^{\mathrm{ab}}$ & $0.016^{\mathrm{bc}}$ & $85.41^{\mathrm{a}}$ & 25 & \\
\hline $0.024^{\mathrm{d}}$ & $0.075^{\mathrm{bc}}$ & $0.042^{\mathrm{ab}}$ & $0.149^{\mathrm{a}}$ & $49.43^{\text {abcd }}$ & $45.83^{\mathrm{ab}}$ & $42.96^{\mathrm{dc}}$ & $82.12^{\mathrm{ab}}$ & $0.025^{\mathrm{ab}}$ & $68.75^{\mathrm{abc}}$ & 10 & \\
\hline $0.014^{\text {cde }}$ & $0.065^{\text {bcd }}$ & $0.018^{\mathrm{de}}$ & $0.088^{\mathrm{e}}$ & $45.42^{\mathrm{dc}}$ & $43.33^{\mathrm{abc}}$ & $44^{\mathrm{bc}}$ & $76.13^{\mathrm{ab}}$ & $0.015^{\mathrm{c}}$ & $33.33^{\mathrm{d}}$ & 40 & \multirow[t]{3}{*}{ salicylic acid } \\
\hline $0.019^{\mathrm{bcd}}$ & $0.101^{\mathrm{ab}}$ & $0.012 \mathrm{e}$ & $0.115^{\text {bcde }}$ & $59^{\mathrm{a}}$ & $40.16^{\mathrm{bcd}}$ & $43^{\mathrm{bc}}$ & $109.2^{\mathrm{a}}$ & $0.016^{\mathrm{c}}$ & $53.12^{\mathrm{dc}}$ & 25 & \\
\hline $0.01^{\mathrm{de}}$ & $0.059^{\mathrm{bc}}$ & $0.032^{\mathrm{bc}}$ & $0.105^{\mathrm{de}}$ & $53.5^{\mathrm{abc}}$ & $46.15^{\mathrm{ab}}$ & $54^{\mathrm{a}}$ & $83.7^{\mathrm{ab}}$ & $0.015^{\mathrm{c}}$ & $71.87^{\mathrm{abc}}$ & 10 & \\
\hline $0.009^{\mathrm{e}}$ & $0.038^{\mathrm{c}}$ & $0.027^{\mathrm{dc}}$ & $0.109^{\text {cde }}$ & $47.33^{\mathrm{bcd}}$ & $38.5^{\mathrm{bcd}}$ & $35^{\mathrm{d}}$ & $58.8^{\mathrm{b}}$ & $0.023^{\mathrm{abc}}$ & $60.417^{\mathrm{bc}}$ & - & control \\
\hline
\end{tabular}

افزايش رشد گياهجه ها نسبت به شاهد شد. تيمار • ا ميلىتسلا به مدتزمان ها دقيقه بهعنوان تيمار مناسب در نظر گرفته شد.

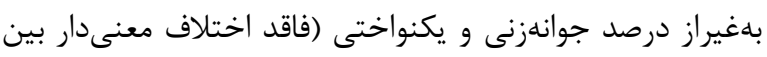
تيمارها)، ميدان مغناطيسى باعث ارتقاى كليه صفات جوانهزنى بذرهاى بنه بهطور معنى دارى شد. مطالعات بر روى سلولهاى

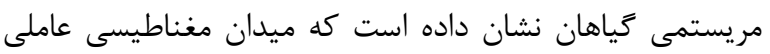

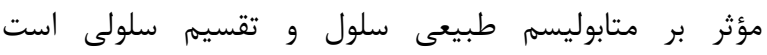
(Fomicheva et al., 1992). در مطالعات انجامشده مشاهده شده است كه در برخى كياهان فعاليت آنزيمهاى آلفا آميلاز،

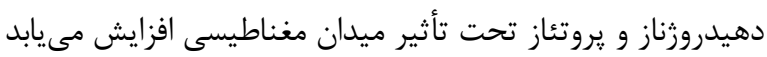
كه بلعنوان محركى براى جوانهزنى سريع خواهد بود ( et al., Pourakbar 2012 (P) مطالعات محققان ديخر نشان داد كه ميدان مغناطيسى باعث افزايش فعاليت آنزيمهاى هيدروليزكننده نظير مئري آلفا آميلاز، دهيدوزناز و يروتئاز شده است كه اين امر به جوانه زنى سريعتر و بهبود بنيه بذر و خصوصيات بهتر ريشهجه در بذرهاى تيمار شده منجر مىشود ) Vashisth \& Nagarajan, 2010). اين مطالعات با نتايج تحقيق حاضر همراستا هستند زيرا افزايش رشد قابلملاحظهاى در طول ساقهُه و ريشهجه ايجاد

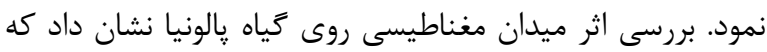

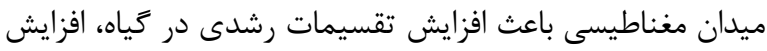
رشد، افزايش سيتوكنين و اكسين، تحريك سنتز يروتئين و ارتقاء

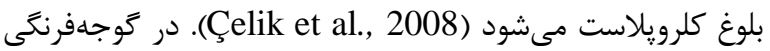
كاهش معنى دار سرعت جوانهزنى بذرهاى مغناطيس شده گزارش شده است (Martinez et al., 2009). در تحقيق حاضر بذرها مهنى
با تيمار برتر يعنى • ا ميلىتسلا نشان دادهده است. ״رايمينگ بذرها در اين شرايط كليه شاخصهاى جوانهزنى مورداندازهخيرى را نسبت به شاهد بهبود بخشيد. بيشترين درصد جوانهزنى مربوط به

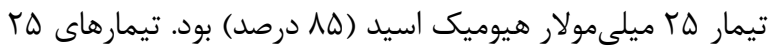

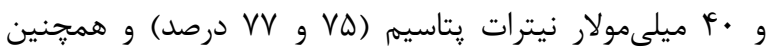

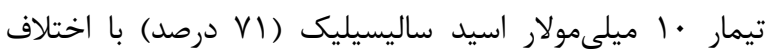
جزئى در رتبه بعدى قرار گرفتند و اين در حالى است كه بذرهاى

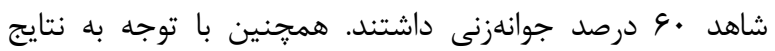

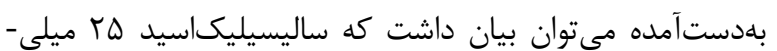
مولار، باعث بيشترين يكنواختى جوانهزنى در بين يِيش تيمارهاى

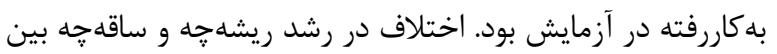
بذرهاى ريش تيمار شده و بذرهاى ييش تيمار نشده آشكار است، بهطورى كه بذرهاى پيش تيمار شده از طول ريشه بيشترى برخوردار بودند (جدول \&)). با بررسى همهجانبه و با توجه

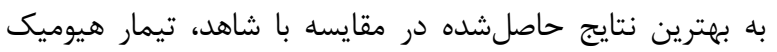
اسيد ها ميلىمولار بهعنوان بهترين تيمار در نظر كرفته مئشود زيرا بالاترين درصد جوانهزنى، بالاترين طول زياهجه ( (1) ميلى بيشتر از شاهد) را ايجاد نمود باوجوداينكه بيشترين طول ريشه جه

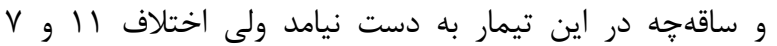
ميلىمترى در اين دو صفت مشاهده شد.

\section{بحث}

براساس نتايج بهدستآمده، ميدان مغناطيسى بر شاخصهاى

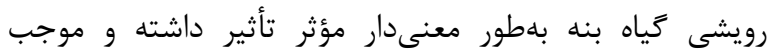




\section{REFERENCES}

Abou El-Yazied, A., Shalaby, O.A., El-Gizawy, A.M., Khalf, S.M. \& Satar, A.El. 2011. Effect of magnetic field on seed germination and transplant growth of tomato. J. Amer. Sci. 7: 306-312.

Aladjadjiyan, A. 2007. The use of physical methods for plant growing stimulation in Bulgaria. J. Cent. Eur. Agric. 8: 369-380.

Aladjadjiyan, A. 2010. Influence of stationary magnetic field on lentil seeds. Inter. Agrophys. 24: 321-324.

Ashraf, M. \& Foolad, M.R. 2005 Pre-sowing seed treatment-ashotgun approach to improve germination, plant growth, and crop yield under saline and non saline conditions. Advances Agro. 88: 223-265.

Basra, S.M.A., Ashraf, M., Iqbal, N., Khaliq, A. \& Ahmad, R. 2004. Physiological and biochemical aspects of pre-sowing heat stress on cotton seed. Seed Sci. Technol. 32: 765-774.

Belyavskaya, N.A. 2004. Biological effects due to weak magnetic field on plants. Adv. Space Res. 34: 1566-1574.

Cakmak, T., Dumlupinar, R. \& Erdal, S. 2009. Acceleration of germination and early growth of wheat and bean seedlings grown under various magnetic field and osmotic conditions. Bioelectromagnetics 30: 1-10.

Çelik, Ö., Atak, Ç. \& Rzakulieva, A. 2008. Stimulation of rapid regeneration by a magnetic field in Paulownia node cutures. J. Cent. Eur. Agric. 9: 297-304.

Dhawi, F., Al-Khayri, J.M. \& Hassan, E. 2009. Static magnetic field influence on elements clements composition in date (Phoenix dactylifera L.). Res. J. Biol. Sci. 5: 161-166.

Feizi, H. \& Rezvani Moghaddam, P. 2011. Influence of magnetic field and silver nano particles in comparison to macro and micro nutrient fertilizers on growth, yield and silage quality of maize. J. Water Soil 24: 1062-1072.

Fomicheva, V.M., Zaslavskii, V.A., Govarun, R.D. \& Danilov, V.I. 1992. Dynamics of RNA and protein synthesis in the cells of the root meristem of the pea, lentil and flax. Biophys 4: 649-656.

Foti, S., Cosentino, S.L., Patane, C. \& Agosta, G.M.D. 2002. Effects of osmoconditioning upon seed germination of sorghum (Sorghum bicolor L.) under low temperatures. Seed Sci. Technol. 30: 521-533.

Garcia, R.F. \& Arza P.L. 2001. Influence of a stationary magnetic field on water relations in lettuce seeds. Part I: theoretical considerations. Bioelectromagnetics 22: 589-595.

Goujani, H.J., Nasr, S.M.H., Sagheb-Talebi, K. and Hojjati, S.M. 2013. Effect of drought stress induced by altitude, on four wild almond species. Iranian J. Poplar Res. 21: 373-386.

Harris, D., Pathan, A.K., Gothkar, P., Joshi, A., Chivasa, W. \& Nyamudeza, P. 2001. On-farm seed priming: using participatory methods to revive and refine a key technology. Agric. Syst. 69: 151-164.

ISTA. 2009. ISTA rules. International Seed Testing Association. Zurich, Switzerland, 60 pp.

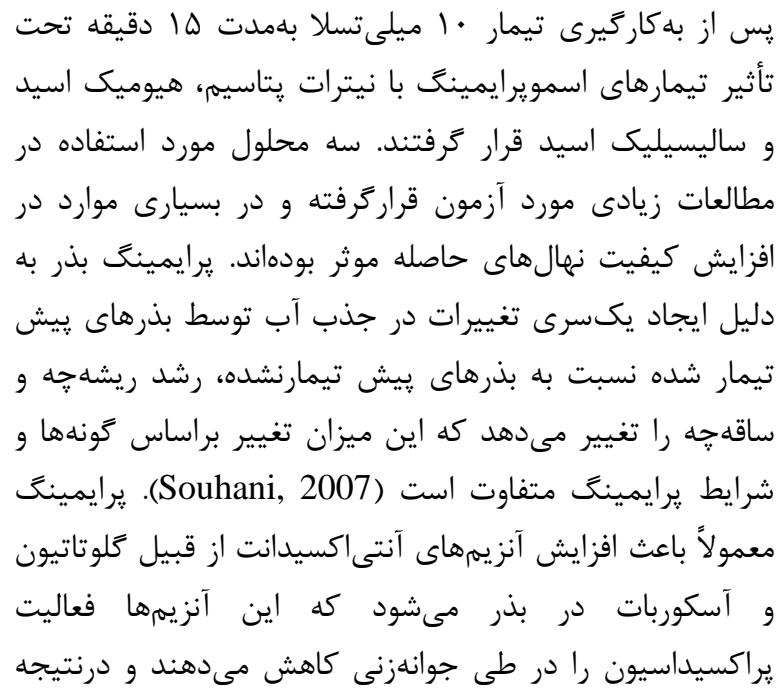

باعث افزايش درصد جوانهزنى مىشوند (Harris et al., 2001). افزايش يتانسيل جوانهزنى، سرعت و يكنواختى جوانهزنى، مقاوم

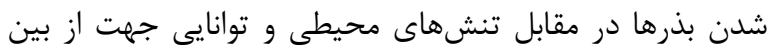

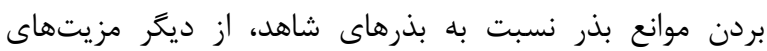

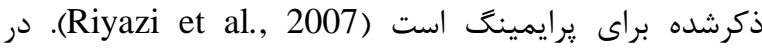
تحقيق حاضر، يرايمينگ بذرهاى قرارگرفته در معرض ميدان

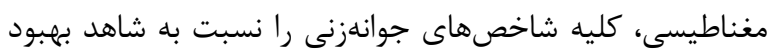

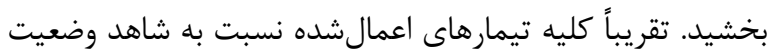

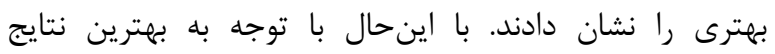

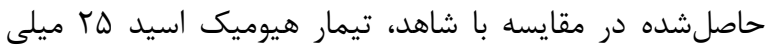
مولار به عنوان بهترين تيمار معرفى مىشود. هيوميك اسيد بلهصورت تيمار بذرى و يا تيمار در خاك، داراى خاصيت شبه

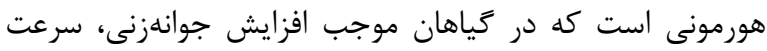
طويل شدن ريشهها، تسريع در رشد شاخهها و تحريك طويل

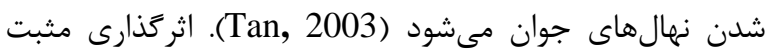
Sheteiwy et al., ) هيوميك اسيد توسط محققين ديخرى Mashahiri \& Hassanpour Asil, 2018 2017; كزارش شده است. با توجه به هزينه يايين خريد و يا ساخت

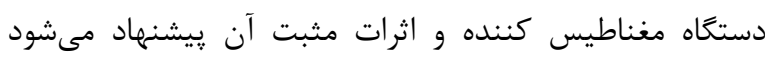

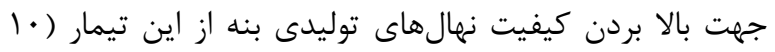

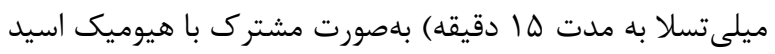

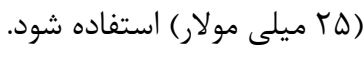

$$
\begin{aligned}
& \text { سياسگز ارى } \\
& \text { بدينوسيله از دكتر راضيه جعفرى حاجتى كه در اين يزوهش } \\
& \text { همكارى نمودهاند، قدردانى مىشود. }
\end{aligned}
$$


Khan, A.Z., Shahi, S., Khan, T., Rehmano, A., Akbari, H., Muhammadi, A. \& Khalil, S.K. 2017. Influence of seed invigoration techniques on germination of Maize. Cercetări Agronomice în Moldova. 3: 61-70.

Khatamsaz, M. 1989. Anacardiaceae. In Assadi, M. et al. (eds.): Flora of Iran, no. 3. RIFR, Tehran.

Kordas, L. 2002. The effect of magnetic field on growth, development and the yield of spring wheat. Polish J. Environm. Stud. 11: 527-530.

Martinez, E., Carbonell, M.V., Amaya, J.M. \& Maqueda, R. 2009. Germination of tomato seeds (Lycopersicon esculentum L.) under magnetic field. Int. Agrophys. 23: 45-49.

Mashahiri, Y. \& Hassanpour Asil, M. 2018. Effects of gibberellic acid and humic acid on some growth characters of Daffodil (Narcissus jonquilla cv. German). Iranian J. Hort. Sci. 48: 875-886.

Murungu, F.S., Chiduza, C., Nyamugafata, L.J. \& Whalley, W.R. 2003. Effects of on-farm seed priming on consecutive daily sowing occasions on the emergence and growth of maize in semi-arid Zimbawe. Field Crop Res. 89: 49-57.

defence system of sweet sorghum (Sorghum bicolor) under salinity and temperature stresses. Crop Pasture Sci. 66: 145-157.

Pourakbar, L., Asadi Samani, M. \& Ashrafi, R. 2012. Effect of magnetic fields on germination, early growth characteristics and activities of some enzymes in Nigella sativa L. seeds. J. Plant Biol. 4: 29-38.

Riyazi, A., Sharifzadeh, F. \& Ahmadi, A. 2007. Effects of osmopriming on seeds germination of forage millet. Res. Develop. Agri. Hort. 77: 72-83.

Sedaghathoor, S., Ahmadi Lashaki, M., Hashemabadi, D. \& Kaviani, B. 2015. Physiological response to salinity stress by primed seeds of three species of lawn. Crop Prod. Proc. 4: 1-10.
Singh, A., Dahiru, R., Musa, M. \& Haliru, B.S. 2014. Effect of osmopriming duration on germination, emergence, and early growth of cowpea (Vigna unguiculata (L.) Walp.) in the Sudans of Nigeria. Int. J. Agron. DOI: 10.1155/2014/841238.

Sheteiwy, M.S., Guan, Y., Cao, D., Li, J., Nawaz, A., Hu, Q., Hu, W., Ning, M. \& Hu, J. 2015. Seed priming with polyethylene glycol regulating the physiological and molecular mechanism in rice (Oryza sativa L.) under nano-ZnO stress. Sci. Rep. 5: $1-14$.

Sheteiwy, MS., Dong, Q., A, J., Song, W., Guan, Y., He, F., Huang, Y. \& Hu, J. 2017. Regulation of ZnO nanoparticles-induced physiological and molecular changes by seed priming with humic acid in Oryza sativa seedlings. Plant Growth Regul. 83: 27-41.

Soltani, A., \& Maddah, V. 2010. Simple, applied programs for education and research in agronomy. Iranian Scientific Society of Agroecol. Publ. 80 pp.

Souhani, M.M. 2007. Seed control and certification. Guilan University Press. 287 pp.

Tan, K.H. 2003. Humic matter in soil and the environment. Marcel Dekker, New York. 408 pp.

Vashisth, A. \& Nagarajan, S. 2010. Effect on germination and early growth characteristics in sunflower (Helianthus annuus) seeds exposed to static magnetic field. J. Plant Physiol. 167: 149-156.

Vasilevski, G. 2003. Perspectives of the application of biophysical methods in sustainable agriculture. Bulgarian J. Plant Physiol, 3-4: 179-186.

Zahedi Pour, H. Fattahi, M. Mirdavodi Akhavan, H.R. \& Azdo, Z. 2004. Study of the distribution, ecology and phenology in the Markazi Province. Res. Dev. 64: 97-103.

How to cite this article:

Payamenoor, V., Hasani Satehi, A., Atashi, S. \& Rezaii Asl, A. 2020. The effects of magnetism and osmopriming on seed germination and vegetative characteristics of Pistacia atlantica. Nova Biologica Reperta 7: 85-91. (In Persian).

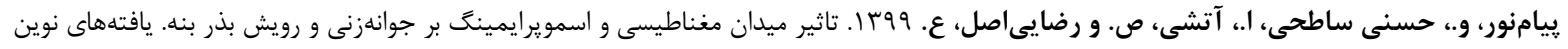

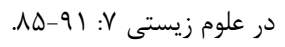

